\title{
Working Memory Capacity For Faces With Different Levels of Emotional Valence
}

\author{
Airton Rodrigues ${ }^{1}$ \\ Mikeael Cavallet ${ }^{2}$ \\ Cesar Alexis Galera² \\ ${ }^{1}$ Centro Paula Soura, São Paulo, São Paulo, Brasil \\ ${ }^{2}$ Universidade de São Paulo, São Paulo, São Paulo, Brasil
}

\begin{abstract}
The capacity of visual working memory (VWM) depends on the complexity of the stimuli being processed. Emotional characteristics increase stimulus complexity and can interfere with the competition for cognitive resources. Studies involving emotional information processing are scarce and still produce contradicting results. In the present study, we investigated the capacity of VWM for faces with positive, negative, and neutral expressions. A modified change-detection task was used in two experiments, in which the number of faces and the emotional valence were manipulated. The results showed that VWM has a storage capacity of approximately two faces, which is fewer than the storage capacity identified for simpler stimuli. Our results reinforce the evidence that working memory can dynamically distribute its storage resources depending on both the amount and the emotional nature of the stimuli.

Keywords: visual working memory; working memory; facial expressions; emotional valence
\end{abstract}

Capacidade da Memória de Trabalho para Faces de Diferentes Valências Emocionais

\begin{abstract}
Resumo
A capacidade da Memória Visual de Trabalho (MTV) depende da complexidade dos estímulos que estão sendo processados. As características emocionais aumentam a complexidade do estímulo e podem interferir na competição por recursos cognitivos. Estudos envolvendo processamento de informações emocionais são escassos e ainda produzem resultados contraditórios. No presente estudo, investiga-se a capacidade da MTV para faces com expressões positivas, negativas e neutras. Uma tarefa modificada de detecção de mudança foi usada em dois experimentos, nos quais o número de faces e a valência emocional foram manipulados. Os resultados mostraram que a MTV tem uma capacidade de armazenamento de aproximadamente duas faces, menor que a capacidade de armazenamento identificada para estímulos mais simples. Os resultados reforçam as evidências de que a memória de trabalho consegue distribuir dinamicamente seus recursos de armazenamento em função tanto da quantidade como da natureza emocional dos estímulos.
\end{abstract}

Palavras-chave: memória de trabalho visual, memória de trabalho, expressões faciais, valência emocional

\section{Capacidad de la Memoria de Trabajo para Rostros con Diferentes Niveles de Valencia Emocional}

\section{Resumen}

La capacidad de la memoria de trabajo visual (MTV) puede variar dependiendo de la complejidad de los estímulos procesados. Las características emocionales aumentan la complejidad del estímulo y pueden interferir con la competencia por los recursos cognitivos. Los estudios que relacionan el procesamiento de informaciones emocionales son todavía escasos y aún producen resultados contradictorios. En el presente estudio, investigamos la capacidad de la MTV de rostros con valencia emocional positiva, negativa y neutra. Se utilizó una tarea de detección de cambios modificada en dos experimentos, en los que se manipuló la cantidad de rostros y niveles de valencia emocional. Nuestros resultados refuerzan la evidencia de que la memoria de trabajo es capaz de distribuir dinámicamente sus recursos de almacenamiento dependiendo tanto de la cantidad, como de la naturaleza emocional de los estímulos.

Palabras clave: memoria de trabajo visual; memoria de trabajo; expresiones faciales; valencia emocional

\section{Introduction}

The visual working memory (VWM) is defined by a set of functions for storing and processing visual information necessary to carry out various tasks. This cognitive system acts as an interface between the environmental demands and long-term knowledge involved in the execution of complex tasks that require reasoning, comprehension, and learning (Baddeley, 2018). The
VWM has limited capacity regarding both the amount of information stored and how long such information can remain active (Baddeley, 2018; Luck \& Vogel, 2013). Some experimental evidence suggests that the storage capacity of VWM is fixed, of approximately 3 to 4 items (Awh, Barton \& Vogel, 2007; Luck \& Vogel, 2013). Other studies indicate that its capacity can vary depending on the complexity of the stored stimuli, decreasing for more complex stimuli such as faces 
(Alvarez \& Cavanagh, 2004; Eng, Chen \& Jiang, 2005). According to Eng et al. (2005), the VWM capacity for faces without emotional valence and for drawing cubes can be of up to 2 items, increasing for polygons (2.5 items) and colors and letters (3.5 items).

Facial expressions are regarded as a type of complex stimulus due to the processing of various micro-expressions that characterize them (Švegar, 2011; Calvo, Avero \& Lundqvist, 2006). Similar to Eng et al. (2005), Švegar (2011) used a change detection task to estimate VWM capacity for faces with different emotional expressions. The change detection task requires the participant to memorize a set of items and, after a retention interval, facing a testing screen, judge whether the stimuli in the test screen are the same or different from those memorized. In Švegar's study, participants should remember a set of seven faces (of the same person) per test, of which six were of emotional expressions (fear, anger, disgust, joy, sadness, and fright) and one neutral face. During coding, six faces were presented simultaneously in six fixed locations, distributed in a circular manner around the center of the screen. The results showed that the ability of VWM was of 3 faces with emotional valence (Švegar, 2011). The presentation of faces always in the same locations and the use of faces from the same individual for testing may have contributed to the greater capacity found. This estimate is higher than that obtained by Eng et al. (2005) for neutral faces, and it is contrary to the idea that neutral faces have higher storage capacity.

Different and sometimes conflicting results have been observed regarding the role of the stimuli's emotional valence plays on VWM. While studies indicate that the participants' performance is affected by the emotional valence of the memorized stimuli (Bergmann, Rijpkema \& Fernández, 2012; Lindström \& Bohlin, 2011; Švegar, Kardum \& Polic, 2013), others show that valence does not affect the performance of VWM (Bannerman et al., 2012; Grimm, Weigand, Kazzer, Jacobs, \& Bajbouj, 2012; Kensinger \& Corkin, 2003). In the study by Lindström and Bohlin (2011), for example, positive stimuli (sex scenes) and negative stimuli (violent death scenes), both with high arousal, provided greater accuracy in a VWM task (2-back) than neutral stimuli of low arousal. The results from Bergmann et al. (2012) also indicate an advantage for emotional valence when recognizing positive valence images with low excitability. The results of Švegar et al. (2013) in a change detection task for faces with different emotional expressions show that the faces expressing joy had a higher rate of correct responses than other expressions such as fear, anger, disgust, sadness, surprise and neutral. Švegar et al. (2013) suggest that the cognitive system prioritizes happy faces as they are a valuable way to establishing and maintaining cooperative relationships with other members of the species.

On the other hand, Kensinger and Corkin (2003) found that the emotional content of pictures or words with negative valence did not interfere with working memory tasks compared to stimuli without emotional valence. The stimuli with negative valence were better remembered only in the long-term memory task used in the study. Similar results were obtained by Bannerman et al. (2012) when they verified that faces expressing negative emotional valence (anger) or positive (joy), presented in different spatial locations, did not increase the ability of spatial memory to neutral faces. Neuroimaging results also found no difference in performance (reaction time and accuracy) for processing and storing the short term words with a neutral and emotional connotation that were visually presented (Grimm et al. 2012).

However, there seems to be a specificity for faces expressing anger, which seems to have a larger storage capacity than happy and neutral faces (Jackson, Wu, Linden \& Raymond, 2009). This specificity is evident, especially when the competition for cognitive resources is increased during encoding, by increasing the number of items displayed, and by the presentation of more than one emotional valence simultaneously in the same test (Simione et al., 2014). The best performance obtained in tests with threatening faces would be associated with the hypothesis that these faces would have an advantage concerning attentional selection (Ye et al., 2018). Negative stimuli would have priority in the processing of information, allowing the automatic and involuntary directing of attention towards potentially threatening information (Moriya, Koster \& De Raedt, 2014). This mechanism would automatically allow the negative faces to be faster processed than the neutral and positive faces (Roman et al., 2015), suggesting that the negative valence could act as a visual cue, prioritizing the recognition and favoring the performance of VWM (Asutay \& Västfjäll, 2015; Gotoh, Kikuchi \& Olofsson, 2010).

With that, one can observe opposite directions about the effects of emotions on working memory. If, on the one hand, there are studies that show that emotion does not represent an overload of information and, therefore, would not affect the subjects' memorizing 
abilities, there are also studies that suggest that emotion modulates the capacity of the working memory, changing the prioritization of the processed information. In this study, we sought to assess the capacity of VWM for items with positive and negative emotional valence about stimuli without emotional valence (neutral) using a change detection task which had real faces expressing joy (positive), disgust (negative) and neutral expressions. In two experiments, we manipulated the number of faces presented between the tests and the number of emotional expressions presented simultaneously to increase competition for cognitive resources, as proposed by Simione and colleagues (2014).

\section{Experiment 1}

\section{Method}

\section{Participants}

In this experiment, the participants were 44 men $(M=28.6$ years old, $S D=5.81)$ and 57 women $(M=$ $27.14, S D=5.71)$, selected by convenience and unaware of the main objective of the experiment. The size of this sample, according to the G*Power 3.1.9.4 software (Faul, Erdfelder, Lang, \& Buchner, 2007), gives the variance analysis tests a $0.99 \%$ statistical power (Power $=1-\beta$ error prob. II ) considering the parameters of average effect $(0.25)$ and error probability $\alpha=0.5$.

\section{Material and Stimuli}

We selected for use 65 neutral faces, 65 faces of joy (positive valence) and 65 faces of disgust (negative valence), chosen from the Karolinska Directed Emotional Faces (KDEF) (Lundqvist \& Öhman, 1998) database and the Gur/Kohler Faces (Gur et al., 2001) database. For each valence, the faces used in the experiment were presented only once. The images were edited to grayscale and excluded any element external to the face to avoid that visual cues outside the facial expression could be used to memorize them (Švegar et al., 2013)

The stimuli were projected on a $150 \times 150 \mathrm{~cm}$ white screen, positioned in front of a classroom, using an Epson multimedia projector with 2,300 lumens and a resolution of $1024 \times 768$ pixels. The faces were presented with a height of $27 \mathrm{~cm}$ and a width of $20.5 \mathrm{~cm}$. The data collection was carried out in a room with capacity for 40 students. The subjects were divided into two sessions with 35 people, and one session with 31 . The subjects were seated in desks arranged in aligned rows, directed to the screen, and distributed approximately the same distance between them. The longest distance between the subjects and the display screen was $8.5 \mathrm{~m}$, and the closest was $2 \mathrm{~m}$. The presentation of the stimuli was controlled with the Microsoft PowerPoint ${ }^{\circledR}$ software, and the faces were presented randomly in 24 possible locations evenly distributed in a virtual matrix of $6 \times 4$ positions.

\section{Procedure}

The experimental task was a change detection task. In each trial, the participants memorized a set of faces presented simultaneously on the screen and, after a retention interval, judged if the test faces were the same memorized at the beginning of the trial, despite changes in their locations. The trial number was presented on the screen for $3 \mathrm{~s}$ and was followed by a fixation point ("+") presented for 1s. At the start of the data collection, the participants received a sheet of paper with the heading "ARE THE FACES THE SAME?" and lines numbered from 1 to 48 with two columns (column $1=$ YES; column $2=\mathrm{NO}$ ) where they marked the answer corresponding to each trial with an "X".

The study was balanced both for the variable 'quantity' and for the 'valences'. The faces were presented in trial blocks of incremental load, starting with two, four, six, and eight faces. In each block, there were four recognition trials for each of the emotions (neutral, positive, and negative). Each set of faces was presented simultaneously for a time proportional to the number of faces ( $1 \mathrm{~s}$ per face, i.e., 2 faces $=2 \mathrm{~s}$, $\ldots, 8$ faces $=8 \mathrm{~s}$ ), followed by a white screen during the retention interval of 2s. After the retention interval, the faces presented as test remained on the screen for a time equal to the encoding. Finally, the sentence "Are the faces the same?" was presented for 6s while the participants recorded their answers on the sheet of paper. The participants should answer "yes" if the two sets of faces were the same, and "no" if there were a change in the identity of the faces. In each trial, all the faces presented for memorization had the same emotional value; that is, they were all neutral faces, all positive (joy), or all negative (disgust).

Four training trials were conducted before starting the valid tests. The participants were also oriented and monitored not to express their answers or look at the nearby participants' responses. A representation of the sequence of events can be seen in Figure 1.

The experiment began with 12 trials with 2 faces, followed by 12 trials with 4 faces, 12 trials with 6 faces, 


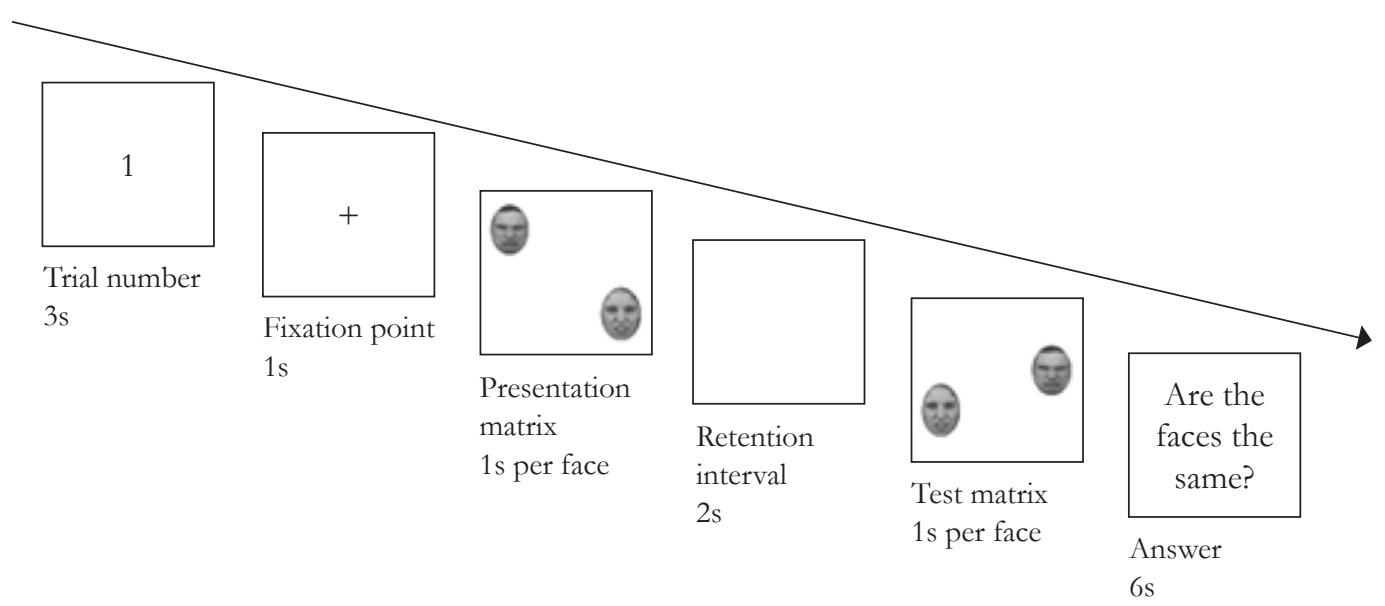

Figure 1. Temporal sequence of events in each test of the change detection task employed in Experiments 1 and 2.

and 12 trials with 8 faces, in 48 trials, for approximately 18 minutes. Each valence (positive, negative, neutral) was presented four times in the 12 trials. In half of the trials, one of the memorized faces' identity was changed to another face of equal valence in the test. In the other half, the faces were the same. The change in face identity and the three emotional valences were randomly presented. The faces shown at the test were in different locations from the faces presented during encoding.

In summary, in this experiment, the memory load $(2,4,6$, and 8 faces) was manipulated between blocks of trials presented in the same sequence for all participants. In each block of trials, the valences were randomized, as well as trials that required positive and negative responses. Thus, all participants underwent an outline with repeated measures in all treatments resulting from the combination of these two experimental factors.

\section{Results and discussion}

The correct response rates of each participant in the trials with the same faces (Hit) and the error rates in the trials with different faces (False Alarm), were used to estimate the discrimination rates $\left(d^{d}\right)$, an index of the participants' sensitivity to discriminate the changes in the identity of the faces (Kellen, Nunes \& GarciaMarques, 2008).

The $d$ 'values of each participant in each treatment were submited to an analysis of variance (ANOVA) $(4 \times 3)$ with repeated measures for the memory load (2,
4, 6 and 8 faces) and valence (neutral, positive and negative). According to this analysis, the performance varied significantly according to the number of faces ( $F$ (3, $\left.303)=52.07, \mathrm{p}=0.00, \eta_{\mathrm{p}}{ }^{2}=0.36\right)$ and also according to emotional valence $\left(\mathrm{F}(2,202)=12.60, \mathrm{p}=0.00, \eta_{\mathrm{p}}{ }^{2}=\right.$ 0.11). The post hoc Bonferroni test $(p<0.05)$ performed on the memory load, showed that the performance on trials with two faces $(M=1.07$, standard error of the meam $=0.06$ ) was better than in other conditions, whereas the averages of $d$ ' for four $(M=0.34, S E M=0.05)$, six $(M=0.23, S E M=0.06)$ and eight $(M=0.19, S E M=$ $0.06)$ faces were not significantly different. The Bonferroni post hoc test showed that the neutral faces had better performance $(M=0.63, S E M=0.05)$ than positive $(M$ $=0.43, S E M=0.05)$ and negative faces $(M=0.34, S E M$ $=0.04)$.

The performance is also affected by the interaction between the load and valence of the faces ( $F(6$, $606)=4.16, \mathrm{p}<0.01, \eta_{\mathrm{p}}^{2}=0.04$ ) (Figure 3). According to the post hoc Bonferroni test $(p<0.05)$ the sensitivity to recognize positive faces was lower $M=0.81$, SEM $=0.09)$ than for neutral $(M=1.24, S E M=0.08)$ and negative faces $M=1.16, S E M=0.08)$ in trials with two faces. In trials with four faces, the sensitivity to the neutral faces $(M=0.60, S E M=0.09)$ and to the positive faces $M=0.46, S E M=0.09)$ were similar, and higher than the sensitivity to recognize the negative faces $M=$ $0.02, \mathrm{SEM}=0.08)$. In the trials with six and eight faces, there were no differences between the valences $(\mathrm{p}<$ 0.97) (Figure 2).

The interaction between memory load and valence suggests that the performance with faces with emotional 
valence depends on the memory load, with working memory capacity higher for neutral faces. In this case, the trials with negative valence are more affected by the memory load than the faces with positive valence. This decrease in sensitivity for detecting changes in negative faces in trials with four or more stimuli suggests that the storage of negative faces demands more cognitive resources, which are also necessary for the retention of faces. These results suggest that VWM's resources are limited but dynamically distributed among visual representations according to the nature of these representations (Hur et al. 2017).

\section{Experiment 2}

In Experiment 1, the faces presented for memorization in each trial were from the same category of emotional valence, not permitting the assessment of possible competition for attention or memory resources between the different valences employed. The presentation of more than one emotional category in the same trial would enable better evaluate the competition for resources (Simione et al., 2014). In Experiment 2, we presented two emotional valences in the same trial. According to Simione et al. (2014), emotionally valued stimuli should have a higher priority concerning neutral items in these conditions. Besides, we used two and four faces per trial because the performance was better than with six and eight faces used in Experiment 1.

\section{Method}

\section{Participants}

A new sample, also chosen based on convenience with 32 male participants $(M=28.23, S D=5.82)$ and 22 females $(M=25.41, S D=5.18)$ took part in the second experiment. The sample size we used has, according to G*Power (Faul et al., 2007), the statistical power of $98.9 \%$ to our analyzes.

\section{Material and Stimuli}

The structure and presentation of the stimuli were the same used in Experiment 1.

\section{Procedure}

The conditions were the same as in Experiment 1, except for the number of faces (i.e., two and four faces) and the number of emotional valence categories displayed at the same time in each trial (i.e., two categories of emotional valence divided equally by the number of faces).

The experimental session started with the presentation of 24 trials with 2 faces, followed by the presentation of 24 trials with 4 faces, totaling 48 trials, and lasting approximately 12 minutes. The emotional valences were presented in the following combination: Neutral and Positive (8 trials); Neutral and Negative (8 trials); Positive and Negative (8 trials). In half of the

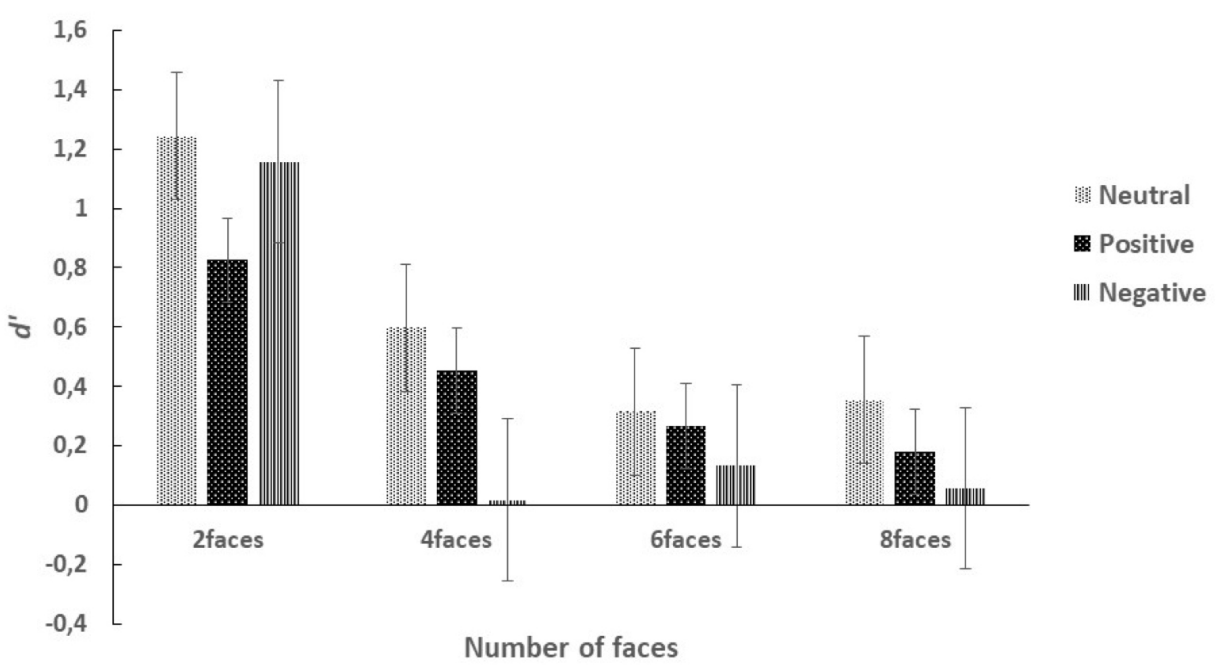

Figure 2. Discrimination indices (d') obtained for Positive, Negative and Neutral valence faces as a function of the number of faces presented for memorization in Experiment 1. The vertical bars show the standard deviation of the mean. 
trials, one faces identity was changed by another with the same emotional valence, and each valence was changed the same amount of time. In the other half, the faces were the same. The design for repeated measures used in this experiment was similar to that used in the previous experiment.

\section{Results and discussion}

The d' was calculated as in Experiment 1, taking into consideration the rates of hits (Hit) and false alarm (False Alarm) obtained with the combinations of emotional valences presented by trial. Six possible combinations of valences were analyzed according to the valence of the unchanged face (fixed) and the changing face in each test: Neutral (fixed) and Positive (changed); Neutral (fixed) and Negative (changed); Positive (fixed) and Neutral (changed); Positive (fixed) and Negative (changed); Negative (fixed) and Neutral (changed); Negative (fixed) and Positive (changed). The data were analyzed by ANOVA $(2 \times 6)$, considering the number of faces displayed ( 2 and 4 faces) and the fixed and changed combinations of valences. This analysis confirmed that the sensitivity for identifying two faces $(M=1.26, S E M=0.07)$ was higher $(\mathrm{F}(1,57)=103.60$, $\left.\mathrm{p}<0.00, \eta_{\mathrm{p}}{ }^{2}=0.65\right)$ than the sensitivity for identifying four faces $(M=0.67, S E M=0.06)$. The performance did not vary significantly with the combination of emotional valences $\left(\mathrm{F}(5,285)=1.80, \mathrm{p}=0.11, \eta_{\mathrm{p}}{ }^{2}=0.03\right)$.
The interaction between the number of faces and the composition of emotional expressions had a marginal effect $\left(F(5,285)=2.80, \mathrm{p}=0.07, \eta_{\mathrm{p}}^{2}=0.03\right)$.

Considering the importance of this interaction between load and valence, also obtained in the previous experiment, we analyzed separately the results obtained with the two and four faces, considering only the combinations between valences. This analysis showed that performance depends on the combination of valences only when the load is two faces $(\mathrm{F}(5,285)=4.01, \mathrm{p}$ $\left.<0.001, \eta_{\mathrm{p}}{ }^{2}=0.07\right)$. The Bonferroni post hoc test ( $\mathrm{p}<$ 0.05 ) showed a statistically significant difference when the combination of faces was Negative (fixed) and Positive (changed). In this case, the performance was worse than for the other combinations $(M=0.98$, SEM $=$ 0.11) (Figure 3).

The results indicate that presenting faces with two types of valence in the same trial impaired the recognition of positive emotional expressions when presented with negative faces. This prejudice occurred in trials with two faces when the positive faces were changed, and the negative faces remained fixed. In the inverse combination, the performance was similar to the other valence compositions evaluated. These results suggest that the negative faces had an advantage over the positive faces since, when presenting the two types of valences together, the participants were less efficient in detecting the change in the positive face. These results suggest that the negative face has gained priority in

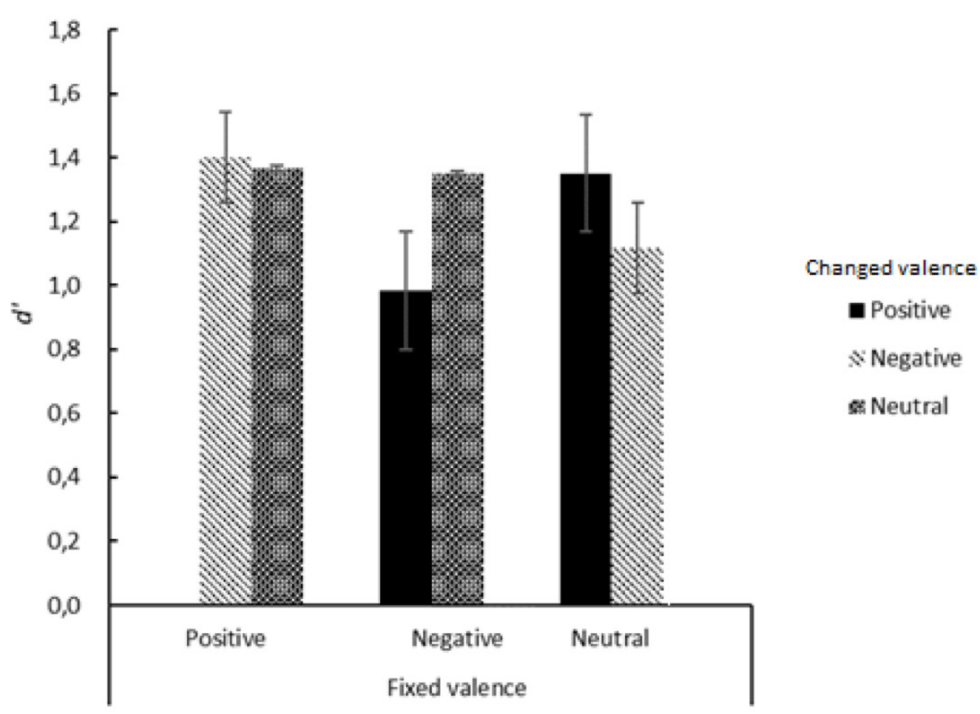

Figure 3. Discrimination indices (d') obtained in the identification of changes in conditions of heterogeneous presentation of the faces of Experiment 2. The vertical bars represent the standard deviation of the mean. Particularly for neutral faces, the standard deviation is very small. 
processing over the positive face. However, this advantage is not higher than the advantage observed for the neutral faces, which did not suffer interference from the other emotional valences when presented simultaneously with the neutral faces. This result is contrary to the results obtained by Simione et al. (2014), indicating that emotional expressions did not have a higher priority over neutral items.

\section{General Discussion}

In this study, we investigated the relationship between VWM and the ability to store faces with different emotional valences. The results show that working memory can store two faces. This result matches the capacity obtained by Eng et al. (2005) to neutral faces and is one less than the capacity of three emotional faces obtained by Švegar (2011). Similarly to our study, Eng et al. (2005) showed the items at randomly selected locations of a virtual matrix of $4 \times 3$ locations, while in Švegar (2011), the faces were always displayed in six locations distributed in a circle around the fixation point during encoding and recognition. During the recognition test, Švegar presented only one face, while Eng et al. presented two faces. In this study, the number of faces during recognition was equal to the number of faces presented during encoding. Another difference was the identity of faces presented by trial. Švegar manipulated different emotional expressions from the same person, while in this study, the faces were from different people. The presentation of faces in different locations, the use of more than one item during the recognition test and the different face identities in the same trial makes the task more complex, as it requires the processing of these factors and may be the reason for the slight variation in the observed VWM capacity.

The results also show that the performance varied according to the facial expressions. The neutral faces were superior to emotional faces, which does not confirm the results observed in studies that evaluated the relationship between the VWM and emotional valence of items (Engen et al., 2017). Our results do not confirm the assumption that there would be a larger VWM storing capacity for emotional stimuli than neutral stimuli, including when the competition for cognitive resources is greater (Simione et al. 2014). One reason for this effect may be that the studies mentioned did not manipulate the number of items displayed by the test to evaluate the capacity of VWM. When the number of items is changed, the capacity for emotional expressions can be affected by the competition for cognitive resources between the faces of emotional valence, while the neutral faces would have an advantage because they are less complex (Švegar, 2011; Calvo et al. 2006). The performance variation obtained in Experiment 1 for negative and positive emotional expressions, according to the number of faces presented, reinforces the proposal that the ability of VWM varies depending on the complexity of the items (Alvarez \& Cavanagh, 2004), contrary to the proposal that the capacity is fixed at 3-4 items (Awh et al., 2007). The results obtained in Experiment 2 also point in this direction, by showing that the increased competition for cognitive resources interfered with the faces with emotional valence, but not with neutral faces.

Considering only the comparison between the emotional expressions of joy and disgust, the results of Experiment 1 indicate an advantage of disgust over the expression of joy when VWM is within its capacity. When the number of items increased to four, the positive items had an advantage over the negative items above the storage capacity. In Experiment 2, the negative valence had an advantage again over the positive when the two valences were under direct competition, being presented simultaneously and within VWM capacity. Similar to what was proposed by Simione et al. (2014) the explanation for these results can be based on the attention load and cognitive control theory proposed by Lavie, Hirst, De Fockert, and Viding (2004). According to this theory, under conditions that do not require all the cognitive processing capacity, there are resources left for the perception of irrelevant information, and the opposite occurs when conditions demand a higher perceptual load. However, unlike Simione et al. (2014), the results indicate that the advantage of the negative expressions occurred when VWM was within its capacity (two faces). Although there is a difference between the negative expressions used in each study (disgust vs. anger), according to Calvo et al. (2006), harrowing emotional expressions would attract attention simply because they show a negative affection, gaining priority in our cognitive system. The better performance would be associated with the hypothesis that threatening faces would have an advantage about attention selection (Asutay \& Västfjäll, 2015; Gotoh, et al., 2010; Moriya et al. 2014; Román et al., 2015).

On the other hand, studies show that faces of joy would be recognized more easily than sad faces in a position where the attention is distributed across the visual field, suggesting that a cheerful face would 
process automatically even when visual attention was engaged in processing other information (Becker \& Srinivasan, 2014; Srinivasan \& Gupta, 2010). Švegar et al. (2013) found a higher number of correct responses and faster reaction times for positive faces concerning neutral and negative faces, indicating that our cognitive system prioritizes happy faces. They suggested that, at the initial stage of processing of visual information, threatening expressions can be prioritized because we benefit when we quickly detect threatening potential. After attention was initially captured by the expressions of anger, expressions of joy would be processed with priority, as they would signal the possibility of forming and maintaining positive and cooperative relationships between subjects (Švegar et al., 2013). Thus, considering our results, facial expressions of disgust may have prioritized the early stages of processing when attention resources were available. Positive faces had an advantage over negative faces when the system was under higher demand for processing resources, and cognitive adjustment was necessary.

The results are methodologically significant, as they were obtained in a more natural environment for the participants and outside the laboratory, therefore, in a more ecological context. This methodological approach follows the proposals that the research on behavior and human cognitive functions should be investigated in natural environments, and can produce results of greater generalization (Schuster, Mermelstein \& Hedeker, 2015). However, running an experiment in the classroom may have led to less control over factors such as the subjects' ability to discriminate between stimuli and the attention directed to visual stimuli presented throughout the experiments. Specific control of these factors was not performed and can be considered a limitation of the present study. However, the results are consistent and similar to the performance estimates obtained in studies conducted in laboratories (Eng et al., 2005; Švegar et al., 2013). Also, the total duration of each experiment can be considered short, and the participants had enough time to perform their responses, reducing the possibility of fatigue. Specific control of discrimination between the faces may be carried out in experiments in the future with a perceptual task of comparing faces, to eliminate the contribution of VWM and requiring more processing of characteristics of the stimuli, like that performed by Jackson et al. (2009) (Experiment 4) in which they observed no existing differences between discriminating the positive, negative, and neutral faces.
Finally, VWM's ability for facial expressions assessed in an environment outside the laboratory is within the expected estimate, but it is not fixed, varying according to the emotional valence of the items. The emotional expressions performed worse than neutral faces, probably due to the greater complexity of the emotional content. The variation in performance according to the number of emotional expressions presented indicates that VWM can prioritize items according to their emotional content and the demand for resources. However, other experiments must be carried out in a controlled environment in the laboratory and in more ecological environments, to compare the results obtained. Besides, it would be useful to investigate memory in everyday situations such as watching commercials, browsing the internet, or even in a shopping process in a supermarket, to understand how VWM works in a more natural context.

\section{References}

Alvarez, G., \& Cavanagh, P. (2004). The capacity of visual short-term memory is set both by visual information load and by number of objects. Psychological science : a journal of the American Psychological Society / APS, 15(2), 106-11.

Asutay, E., \& Västfjäll, D. (2015). Negative emotion provides cues for orienting auditory spatial attention. Frontiers in Psychology, 6(May), 1-7. http://doi. org/10.3389/fpsyg.2015.00618

Awh E, Barton B, \& Vogel EK (2007). Visual working memory represents a fixed number of items regardless of complexity. Psychol Sci. 18(7), 622-8. https:/ / doi.org/10.1111/j.1467-9280.2007.01949.x

Baddeley, A. (2018). Exploring Working Memory. New York, NY: Routledge.

Bannerman, R. L., Temminck, E. V, \& Sahraie, A. (2012). Emotional stimuli capture spatial attention but do not modulate spatial memory. Vision Research, 65, 12-20. http://doi.org/10.1016/j. visres.2012.05.011

Becker, D. V., \& Srinivasan, N. (2014). The Vividness of the Happy Face. Current Directions in Psychological Science, 23(3), 189-194. http://doi. org/10.1177/0963721414533702

Bergmann H.C., Rijpkema M., Fernández G., \& Kessels R.P. (2012). The effects of valence and arousal on 
associative working memory and long-term memory. PLoS One, 7(12), e52616. doi: 10.1371/journal. pone.0052616

Calvo, M.G., Avero, P., \& Lundqvist, D. (2006). Facilitated detection of angry faces: Initial orienting and processing efficiency. Cognition and Emotion, 20, 785-811. https://doi.org/10.1080/02699930500465224

Eng, H. Y., Chen, D., \& Jiang, Y. (2005). Visual working memory for simple and complex visual stimuli. Psychonomic bulletin \& review, 12(6), 112733. Retrieved from http://www.ncbi.nlm.nih.gov/ pubmed/16615339

Engen, H, G., Smallwood, J., Singer, T. (2017): Differential impact of emotional task relevance on three indices of prioritised processing for fearful and angry facial expressions. Cognition \& emotion 31 (1). doi: 10.1080/02699931.2015.1081873.

Faul, F., Erdfelder, E., Lang, A. G., \& Buchner, A. (2007). G* Power 3: A flexible statistical power analysis program for the social, behavioral, and biomedical sciences. Behavior Research Methods, 39, 175-191. https://doi.org/10.3758/BF03193146

Gotoh, F., Kikuchi, T., \& Olofsson, U. (2010). A facilitative effect of negative affective valence on working memory. Scandinavian Journal of Psychology, 51(3), 185-191. http://doi. org/10.1111/j.1467-9450.2009.00766.x

Grimm, S., Weigand, A., Kazzer, P., Jacobs, A. M., \& Bajbouj, M. (2012). Neural mechanisms underlying the integration of emotion and working memory. NeuroImage, 61(4), 1188-1194. http://doi. org/10.1016/j.neuroimage.2012.04.004

Gur, R.C., Ragland, J.D, Moberg P.J, Turner T.H., Bilker, W.B., Kohler, C., Siegel, S.J., Gur, R.E. (2001). Computerized neurocognitive scanning: I. Methodology and validation in healthy people. Neuropsychopharmacology; 25(5):766-776.

Hur, Juyoen; Iordan, Alexandru D.; Dolcos, Florin; Berenbaum, Howard (2017): Emotional influences on perception and working memory. Cognition \& emotion 31 (6). DOI: 10.1080/02699931.2016.1213703.

Jackson, M.C., Wu C.Y., Linden D.E., \& Raymond J.E. (2009). Enhanced visual short-term memory for angry faces. J Exp Psychol Hum Percept Perform. 35(2), 363-374. doi: 10.1037/a0013895
Kellen, D. Van der, Nunes, L. D., \& Garcia-Marques, L. (2008). Sensibilidade e bom senso : Princípios fundamentais da teoria de detecção de sinal na investigação em Psicologia. Laboratório de Psicologia, 6(1), 75-91. Retrieved from http://publicacoes. ispa.pt/index.php/lp/article/view/694/675

Kensinger, E. A., \& Corkin, S. (2003). Effect of Negative Emotional Content on Working Memory and Long-Term Memory. Emotion, 3(4), 378-393. http:// doi.org/10.1037/1528-3542.3.4.378

Lavie, N., Hirst, A., de Fockert, J. W., \& Viding, E. (2004). Load Theory of Selective Attention and Cognitive Control. Journal of Experimental Psychology: General, 133(3), 339-354. http://dx.doi. org/10.1037/0096-3445.133.3.339

Lindström, B.R., Bohlin G. (2011). Emotion processing facilitates working memory performance. Cognition and Emotion, 25(7), 1196-1204. doi: 10.1080/02699931.2010.527703

Luck, S. J., \& Vogel, E. K. (2013). Visual working memory capacity: from psychophysics and neurobiology to individual differences. Trends in Cognitive Sciences, 17(8), 391-400. http://doi.org/10.1016/j. tics.2013.06.006

Lundqvist, D., Flykt, A., \& Öhman, A. (1998). The Karolinska Directed Emotional Faces - KDEF, CD ROM from Department of Clinical Neuroscience, Psychology section, Karolinska Institutet, ISBN 91-630-7164-9

Moriya, J., Koster, E. H. W., \& De Raedt, R. (2014). The influence of working memory on visual search for emotional facial expressions. Journal of Experimental Psychology: Human Perception and Performance, 40(5), 1874-1890. http://doi.org/10.1037/a0037295

Román, F. J., García-Rubio, M. J., Privado, J., Kessel, D., López-Martín, S., Martínez, K., ... Colom, R. (2015). Adaptive working memory training reveals a negligible effect of emotional stimuli over cognitive processing. Personality and Individual Differences, 74, 165-170. http://doi.org/10.1016/j. paid.2014.10.014

Schuster, R.M., Mermelstein, R.J., \& Hedeker, D. (2015). Acceptability and feasibility of a visual working memory task in an ecological momentary assessment paradigm. Psychol Assess, 27(4), 1463-1470. doi: $10.1037 /$ pas0000138 
Simione, L., Calabrese, L., Marucci, F. S., Belardinelli, M. O., Raffone, A., \& Maratos, F. A. (2014). Emotion based attentional priority for storage in visual short-term memory. PLOS ONE, 9(5), 1-8. http:// doi.org/10.1371/journal.pone.0095261

Srinivasan, N., \& Gupta, R. (2010). Emotion-attention interactions in recognition memory for distractor faces. Emotion (Washington, D.C.), 10(2), 207-215. http://doi.org/10.1037/a0018487

Švegar, D. (2011). Visual Working Memory Capacity for Emotional Facial Expressions. Psychological Topics, 20(3), 489-502. http://hrcak.srce.hr/78730
Švegar D., Kardum I., \& Polic, M. (2013). Happy Face Superiority Effect in Change Detection. Paradigm. Psychological Topics 22 (2), 249-269.

Ye, Chaoxiong; Xu, Qianru; Liu, Qiang; Cong, Fengyu; Saariluoma, Pertti; Ristaniemi, Tapani; Astikainen, Piia (2018): The impact of visual working memory capacity on the filtering efficiency of emotional face distractors. Biological psychology 138. DOI: 10.1016/j.biopsycho.2018.08.009

Recebido em: 20/04/2019 Reformulado em: 10/02/2020 Aprovado em: 01/06/2020

About the authors:

Airton Rodrigues is Graduated in Business Administration at Universidade Presbiteriana Mackenzie, has an MBA in Marketing by FUNDACE/USP, master in Psychology by USP-RP and doctorate in Psychology by USP-RP. Currently teaches at Centro Paula Souza (FATEC) in the Cosmetology course. Co-owner of Popmind Pesquisas, a company specialized in neuroscience studies applied to marketing.

ORCID: https://orcid.org/0000-0002-5055-6352

E-mail: airton.rodrigues@fatec.sp.gov.br

Mikael Cavallet is Graduated in Psychology at Universidade Paulista, master and doctorate in Psychobiology by USP-RP with a one year doctoral stay at Concordia University, Montreal, Canada. Post-doctorate in the Neuroimaging Laboratory of the Department and Institute of Psychiatry at the Faculdade de Medicina at USP - São Paulo. Projects in the areas of Experimental Cognitive Psychology and Cognitive Neuroscience.

ORCID: https://orcid.org/0000-0002-2626-0121

E-mail: cavalletm@gmail.com

Cesar Alexis Galera is a Professor at FFCLRP-USP. Graduated in Psychology at USP-RP, master and doctor in Psychology (Experimental Psychology) by the Psychology Institute at USP, supervised by Professor Arno Engelmann, and post-doctorate at Concordia University (Canada), supervised by Professor Michael von Grünau. Licenced at the Post-Graduation Program in Psychobiology at FFCLRP - USP, in the area of HUman Experimental Psychology.

ORCID: https://orcid.org/0000-0002-3021-7126

E-mail: algalera@usp.br

Contact:

Avenida Luiz Merenda, 443, Jd. Campanário

Diadema-SP, Brasil

CEP: 09931-390 